\title{
Examination of the effects of COVID 19 on corneal endothelium
}

\author{
Seyfettin Erdem ${ }^{1}$ (D) Mine Karahan ${ }^{1} \cdot$ Sedat Ava ${ }^{1} \cdot$ Mehmet Emin Dursun ${ }^{1} \cdot$ Leyla Hazar $^{1} \cdot$ Ugur Keklikci $^{1}$
}

Received: 15 January 2021 / Revised: 22 April 2021 / Accepted: 27 May 2021 / Published online: 7 June 2021

(c) The Author(s), under exclusive licence to Springer-Verlag GmbH Germany, part of Springer Nature 2021

\begin{abstract}
Purpose To demonstrate the effects of the disease on the corneal endothelium in individuals recovering from COVID-19 through specular microscopy.

Methods Eighty individuals recovering from COVID-19 (group 1) and 72 healthy controls (group 2) were included in this prospective study. After examining visual acuity, refractive defect detection, anterior and posterior segment examinations, and specular microscopy measurements were calculated from images with at least 100 cells. The mean cell density (CD), mean coefficient of variation (CV), mean hexagonal cell percentage, mean cell area (AVG), and central corneal thickness (CCT) were evaluated.

Results The mean time from diagnosis of the disease in group 1 was $54.25 \pm 6.36$ days. The mean time elapsed since the PCR test became negative was $38.45 \pm 6.87$ days. Only four were treated in the hospital. Specular microscopy data showed that the CD was $2713.56 \pm 246.25$ and $2845.80 \pm 299.27$ in groups 1 and 2 , respectively $(p=0.003)$. The $C V$ values were $42.92 \pm 6.79$ and $40.16 \pm 5.97$, respectively $(p=0.009)$. The hexagonality were $46.51 \pm 7.35$ and $49.12 \pm 6.87$, respectively $(p=0.024)$. The AVG was $371.60 \pm 34.64$ and $353.16 \pm 35.29$, respectively $(p=0.007)$. The CCT values were 553.00 \pm 73.2 , and $526.84 \pm 33.57$, respectively $(p=0.005)$.

Conclusion A decrease in the number of endothelial cells and hexagonal cells (polymorphism) as well as an increase in the cell area change coefficient (polymegatism) and the average cell area were observed from corneal specular microscopic examination of individuals recovering from COVID-19 in the early period of the disease. These results may be important in understanding the systemic effects of the disease.
\end{abstract}

Keywords COVID-19 · Corneal endothelium · Specular microscopy $\cdot$ Cell density $\cdot$ Coefficient of variation $\cdot$ Hexagonal cell percentage

This article is part of a topical collection on Perspectives on COVID-19.

Seyfettin Erdem

serdem2147@hotmail.com

1 Department Ophthalmology, Dicle University Medical

Faculty, 21280 Sur/Diyarbakır, Turkey 


\section{Key messages}

\section{What was known before}

- It has been reported that SARS-CoV-2 infiltrates human cells through the angiotensin converting enzyme-2 (ACE-2) receptor, and these receptors are known to be expressed in eye tissues such as the cornea and conjunctival epithelial cells. In addition, previous studies have reported that viral RNA was detected in tears and retinal biopsies of COVID-19 patients. In the examination performed in postmortem cornea donors, the presence of SARS-CoV-2 RNA and envelope and spike proteins in the corneas of patients with COVID-19 was observed. In this study, the highest prevalence of SARS-CoV-2 RNA was reported on the posterior corneal (endothelial) surface $(25 \%)$.

\section{What this study adds}

- In this study, a decrease in the number of endothelial cells and hexagonal cells (polymorphism) and an increase in the cell area change coefficient (polymegatism) and in the average cell area were observed in corneal specular microscopic examination in the early period during recovery from COVID- 19.

- As far as we know, this is the first study that investigates the effects of the disease on the corneal endothelium using specular microscopy in individuals recovering from COVID-19.

\section{Introduction}

The corneal endothelial cells, which are made of single-layered, flat, polygonal cells, keep the hydration of the stroma layer at a certain level with their active $\mathrm{Na}+-\mathrm{K}+$ pump feature, and thus play an extremely important function in providing corneal transparency [1]. The corneal endothelial cell density decreases with an annual average decline of $0.3-0.5 \%$ as age progresses, and has been noted to eb $2000-2500$ cells $/ \mathrm{mm}^{2}$ in healthy adults $[2,3]$.

Despite not having the ability to undergo mitosis, corneal endothelial cells have important roles in providing and maintaining the transparency of the cornea both mechanically and by pump mechanisms. Repair of damage to corneal endothelial cells occurs by expansion, migration, and amitotic nucleus division of the remaining endothelial cells. As a result, in cases where endothelial damage occurs, the density and the hexagonality of these cells decreases, with a corresponding proportional increase in the average cell area. Therefore, parameters such as the number, pleomorphism, and hexagonality of these cells are used to evaluate the functional capacity of endothelial cells [4, 5]. Qualitative and quantitative analysis of the corneal endothelium can be performed with a specular microscope that shifts a slit light onto the corneal tissue surface and collects the reflected light on a film plane. The mean endothelial cell density $\left(\mathrm{CD}\right.$, cell $\left./ \mathrm{mm}^{2}\right)$, mean cell area $\left(\mathrm{AVG}, \mu \mathrm{m}^{2}\right)$, coefficient of variation of cell area $(\mathrm{CV}$, $\%$ ), percentage of hexagonality (\%), and central corneal thickness $(\mathrm{CCT}, \mu \mathrm{m})$ are measured by specular microscopy $[4,6]$.

Various viruses such as herpes simplex virus (HSV), varicella zoster virus (VZV), cytomegalovirus (CMV), and paramyxo virus have been reported to cause corneal endothelitis, which can cause irreversible corneal endothelial cell damage and endothelial dysfunction [6-8].

Documenting any changes in COVID-19 is crucial as it causes the pandemic and affects millions of people. The main ocular finding in patients with COVID 19 so far is viral conjunctivitis. In addition, previous studies have reported that viral RNA was detected in the tears and retinal biopsies of COVID-19 patients [9-11]. It has been reported that SARS-CoV-2 infiltrates human cells through the angiotensin converting enzyme-2 (ACE-2) receptor, which are relatively highly expressed in eye tissues such as the cornea and conjunctival epithelial cells [12-14]. Therefore, it is important to find out whether the disease has possible effects on the corneal endothelium, which may cause unusual visual complaints / symptoms in people with COVID 19.

The aim of this study was to compare the effects of the disease using specular microscopy on the corneal endothelium in individuals recovering from COVID-19 with healthy controls who are matched for age and sex. 

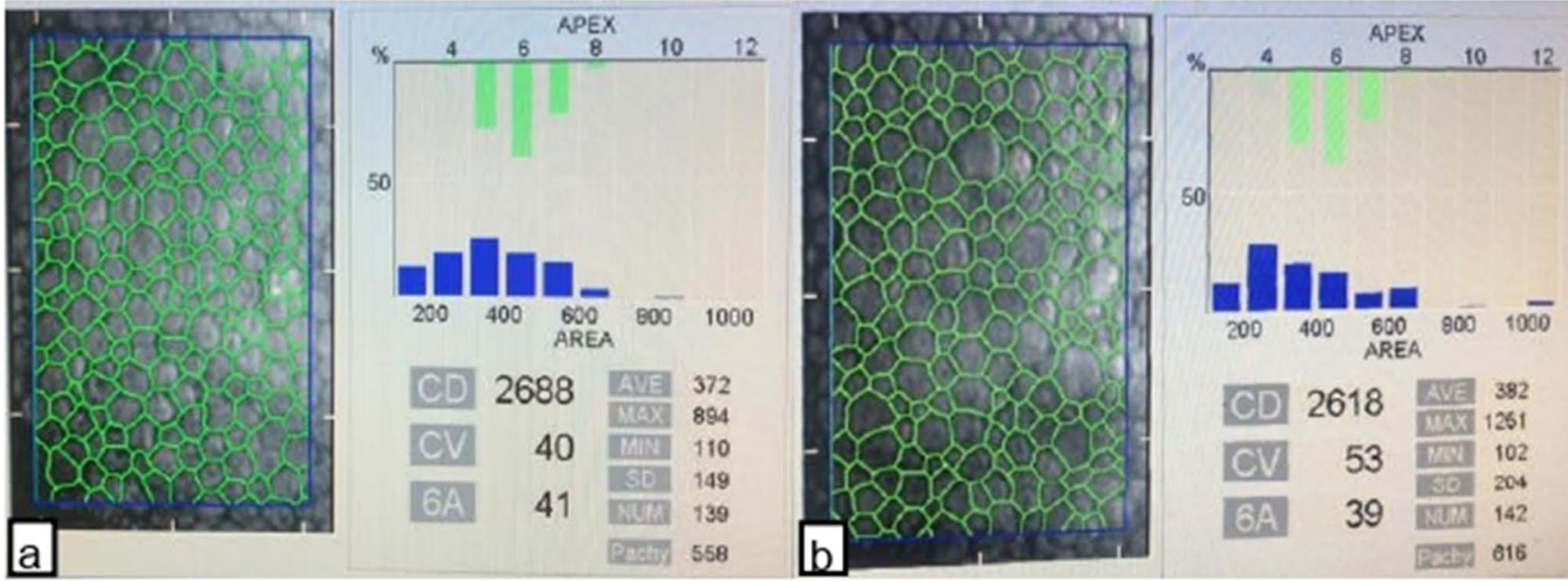

Fig. 1 Specular microscopic findings of $\mathbf{a}$ an individual recovering from COVID-19, $\mathbf{b}$ a control subject are seen

\section{Method}

\section{Study design and subject}

This prospective study included 80 patients who recovered from COVID-19 and 72 healthy controls of similar age and sex. We obtained approval from the Ministry of Health and the Dicle University School of Medicine ethics committee for the study. All study participants gave written consent before the measurement, and the study was carried out according to the Declaration of Helsinki.

Corrected visual acuity determinations, anterior segment, and posterior segment examinations were performed in all subjects included in the study. After specular microscopy measurements were calculated on images with at least 100 cells, corneal endothelial cell number, cell area variation coefficient, and hexagonal cell percentage were determined and evaluated. The study group consisted of people who had COVID 19 and recovered from this disease for at least a month. The control group consisted of people who applied to the ophthalmology clinic for routine examination and had normal eye examination and no history of systemic disease. In both groups, previous ocular surgery, spherical equivalent to two diopters, ocular disease (glaucoma, uveitis, amblyopia, strabismus, dry eye, keratoconus, corneal opacity), those using topical ophthalmic drops, and patients with systemic diseases other than COVID 19, were excluded from the study.

\section{Specular microscopic measurement}

A trained technician masked to the participant group took three images from the central cornea using a non-contact specular microscope to evaluate the corneal endothelium. With the automatic mode of the software program, the image with at least 100 adjacent cells and the image in which the cell borders can be clearly identified was
Table 1 Demographic and clinical characteristics of the subjects included in the study

\begin{tabular}{llll}
\hline Characteristics & $\begin{array}{l}\text { Patients recovering from } \\
\text { COVID-19 }(N=80)\end{array}$ & $\begin{array}{l}\text { Healthy control } \\
(N=72)\end{array}$ & $\begin{array}{l}\text { Significance } \\
(p \text { value })\end{array}$ \\
\hline $\begin{array}{l}\text { Age (years, mean } \pm \text { SD) } \\
\text { Sex, } n(\%)\end{array}$ & $36.37 \pm 7.70$ & $34.66 \pm 5.89$ & 0.125 \\
$\quad$ Female & $44(55.0)$ & $37(51.4)$ & 0.65 \\
$\quad$ Male & $36(45.0)$ & $35(48.6)$ & 0.523 \\
BCVA & $0.97 \pm 0.05$ & $0.98 \pm 0.04$ & - \\
$\begin{array}{l}\text { Time elapsed since the diag- } \\
\text { nosis of the disease (days, } \\
\text { mean } \pm \text { SD) }\end{array}$ & $54.25 \pm 6.36$ & - & - \\
$\begin{array}{l}\text { Time elapsed since the PCR } \\
\text { test was negative (days, } \\
\text { mean } \pm \text { SD) }\end{array}$ & $38.45 \pm 6.87$ & - & \\
\hline
\end{tabular}

BCVA, best-corrected visual acuity 
Table 2 Specular microscopic findings of the subjects included in the study

\begin{tabular}{lccc}
\hline CD $\left(\right.$ cells $\left./ \mathrm{mm}^{2}\right)$ & $2713.56 \pm 246.25$ & $2845.80 \pm 299.27$ & $\mathbf{0 . 0 0 3}$ \\
CV $(\%)$ & $42.92 \pm 6.79$ & $40.16 \pm 5.97$ & $\mathbf{0 . 0 0 9}$ \\
Hexagonality $(\%)$ & $46.51 \pm 7.25$ & $49.12 \pm 6.87$ & $\mathbf{0 . 0 2 4}$ \\
AVG $\left(\mu \mathrm{m}^{2}\right)$ & $371.60 \pm 34.64$ & $353.16 \pm 35.29$ & $\mathbf{0 . 0 0 1}$ \\
CCT $(\mu \mathrm{m})$ & $553.00 \pm 73.29$ & $526.84 \pm 33.57$ & $\mathbf{0 . 0 0 5}$ \\
\hline
\end{tabular}

$C D$, mean cell density; $C V$, mean coefficient of variation; Hexagonality, mean hexagonal cell percentage; $A V G$, mean cell area; $C C T$, central corneal thickness. Bold values indicate statistical significance

selected from the three images obtained from the central cornea. By specular microscopy (Konan Medical Inc., Japan), the CD (cell/ $\mathrm{mm}^{2}$ ), CV (polymegatism, \%), hexagonality (polymorphism, \%), AVG $\left(\mu \mathrm{m}^{2} /\right.$ cell), and mean value of CCT $(\mu \mathrm{m})$ were determined. Each measurement was calculated from images with at least 100 cells (Fig. 1).

\section{Statistical analysis}

SPSS 26.0 version (Chicago, IL, USA) was used for all statistical analysis. Demographic data were calculated using descriptive statistics. Mean and standard deviations were used to describe the data. After all measurements were entered into the program, a normality test was applied. Student $t$-test was used to compare the continuous variables of the two groups according to the normality test's result. Comparison of categorical variables was made using the chi-square test. Pearson's correlation analysis was used for analysis of the correlation.

\section{Results}

The mean time since the diagnosis of the disease in group 1 subjects was $54.25 \pm 6.36$ days, the mean time elapsed since the negative PCR test was $38.45 \pm 6.87$ days, and only four of the patients in group 1 were treated in the hospital (Table 1).

Specular microscopy data showed that the CD was $2713.56 \pm 246.25$ in group 1 and $2845.80 \pm 299.27$ in group $2(p=0.003)$. The $\mathrm{CV}$ values were $42.92 \pm 6.79$ and $40.16 \pm 5.97$ in groups 1 and 2 , respectively $(p=0.009)$. The hexagonality of the groups were $46.51 \pm 7.25$ and $49.12 \pm 6.87$, respectively $(p=0.024)$. Similarly, the AVG was calculated as $371.60 \pm 34.64$ and $353.16 \pm 35.29$, respectively ( $p=0.007)$. In addition, the CCT values of the groups were determined to be $553.00 \pm 73.29$ and $526.84 \pm 33.57$, respectively ( $p=0.005$; Table 2$)$.

\section{Discussion}

This study aimed to compare the effects of COVID-19 on the corneal endothelium with those in normal individuals matched in terms of age and gender using specular microscopy in the early period during recovery from the disease. The corneal specular microscopic examination showed a decrease in the number of endothelial and hexagonal cells (polymorphism) and an increase in the cell area change coefficient (polymegatism) and in the average cell area. In addition, while COVID-19 patients had a lower ECD, it was found that their endothelial parameters remained within the clinically normal range.

The most important function of corneal endothelial cells is to provide corneal transparency, which may be affected by advanced age, previous intraocular surgery, and some systemic diseases [15-17]. Since corneal endothelial cells do not have sufficient mitotic ability to effectively replace cell loss caused by damage, the repair process occurs with the expansion and migration of the remaining cells and division of the amitotic nucleus. As a result, the $\mathrm{CD}$ decreases, the average cell area increases, and the hexagonal cell pattern is disrupted $[4,5]$.

Although the potential transmission of SARS-CoV-2 from the ocular surface is thought to be important, the route of virus transmission to the ocular tissue remains controversial as the presence of SARS-CoV-2 RNA in blood samples has been demonstrated $[18,19]$.

CCT measurement can be used to evaluate corneal endothelial function. It has been reported that CCT may increase due to the decrease in the endothelial cell density and the temporary functional failure of the endothelial $\mathrm{Na}+/ \mathrm{K}+$ - ATPase pump which may develop due to increased intraocular pressure and inflammation [20,21] In COVID-19, organs expressing ACE-2 reportedly develop an insufficient adaptive immune response during the early stages of viral replication and an excessive innate immune response during the later stages. Additionally, in a corneal transplant patient, COVID-19 may disrupt the balance of immunoregulatory responses that allow the graft to survive by allowing antigen-presenting cells to access the protected graft sites with a proinflammatory effect [22]. The results of these studies above suggest that the higher CCT we observed in the COVID-19 group in our study may have been caused by the endothelial cell function impaired by the immune dysregulation and proinflammatory effect that developed in these patients [23].

Consistent with the results of our study, in a study in which patients diagnosed with corneal endothelitis by PCR and positive for CMV, HSV, VZV were examined using corneal in vivo confocal microscopy, while it was reported that the endothelial cell density was significantly lower, 
basal epithelial cells were and anterior keratocyte densities were reported to be significantly higher and corneal edema was present in all patients [23].

In the examination performed on postmortem cornea donors, the presence of SARS-CoV-2 RNA and envelope and spike proteins were found in the corneas of COVIDpositive patients and asymptomatic patients as $11 \%$ and $15 \%$, respectively. In this study, the highest prevalence of SARSCoV-2 RNA was reported on the posterior corneal (endothelial) surface (25\%) [24]. Previous studies have considered that the tear film, which contains molecules with higher antimicrobial activity such as lactoferrin, may result in the prevention of SARS-CoV-2 from binding to ACE-2 receptors on the anterior cornea and conjunctival surfaces [18]. The results of this study may explain the findings of our current study, in which we detected a decrease in the number of endothelial and hexagonal cells (polymorphism), an increase in the cell area change coefficient (polymegatism) and mean cell area. These findings may be the result of the early effects of COVID-19 on the corneal endothelium.

The limitations of this study include the cross-sectional nature of the study conducted in a single center on a relatively small number of participants. Although no participant in the control group had symptoms, signs and history of contact with a patient with COVID-19, the possibility of some of the control participants to have asymptomatic COVID-19 cases in this study can be considered as another limitation. Meanwhile, the potentially valuable aspect of this study is that this is the first study to report the effects of COVID-19 on the corneal endothelium using specular microscopy in individuals recovering from the disease as far as we know.

In conclusion, a decrease in the number of endothelial and hexagonal cells (polymorphism) and an increase in the cell area change coefficient (polymegatism) and average cell area were observed in corneal specular microscopic examination in individuals recovering from COVID-19 during the early period of recovery. The findings of our study may be due to either an insufficient response or impaired immunoregulatory responses to early viral replication in the cornea, which expresses ACE-2. Future large-scale, multi-center, long-term studies must further investigate these findings.

Author contributions Study design: S.E., M.K., S.A., L.H.; study intervention: S.E., M.K., S.A., M.E.D., U.K.; methodology: S.E., S.A., M.E.D., U.K.; formal analysis: S.E., M.K., S.A., U.K; writing-original draft preparation: S.E. M.E.D., L.H., S.A, U.K., M.K.; writing-review and editing:: S.E. M.E.D., L.H., S.A, U.K.; visualization: S.E. M.E.D., L.H., S.A, U.K., M.K.;supervision: S.E., M.K., M.E.D.,U.K.

\section{Declarations}

Ethics approval All procedures performed in studies involving human participants were in accordance with the ethical standards of the insti- tutional and/or national research committee and with the 1964 Helsinki Declaration and its later amendments or comparable ethical standards.

Informed consent Informed consent was obtained from all individual participants included in the study.

Conflict of interest The authors declare that they have no conflict of interest.

\section{References}

1. Qazi Y, Wong G, Monson B et al (2010) Corneal transparency: genesis, maintenance and dysfunction. Brain Res Bull 81:198 210. https://doi.org/10.1016/j.brainresbull.2009.05.019

2. Yee RW, Matsuda M, Schultz RO, Edelhauser HF (1985) Changes in the normal corneal endothelial cellular pattern as a function of age. Curr Eye Res 4:671-678. https://doi.org/10.3109/02713 688509017661

3. Carlson KH, Bourne WM, McLaren JW, Brubaker RF (1988) Variations in human corneal endothelial cell morphology and permeability to fluorescein with age. Exp Eye Res 47:27-41. https:// doi.org/10.1016/0014-4835(88)90021-8

4. Mishima S (1982) Clinical investigations on the corneal endothelium XXXVIII Edward Jackson memorial lecture. Am J Ophthalmol 93:1-29. https://doi.org/10.1016/0002-9394(82)90693-6

5. Tuft SJ, Coster DJ (1990) The corneal endothelium. Eye 4:389424. https://doi.org/10.1038/eye.1990.53

6. Ophthalmology AA of (1991) Corneal endothelial photography. Ophthalmology 98:1464-1468. https://doi.org/10.1016/S01616420(91)32110-9

7. Porzukowiak TR, Ly K (2015) In vivo confocal microscopy use in endotheliitis. Optom Vis Sci 92:e431-e436. https://doi.org/10. 1097/OPX.0000000000000729

8. Kobayashi R, Hashida N, Soma T et al (2017) Clinical findings of anterior segment spectral domain optical coherence tomography images in cytomegalovirus corneal endotheliitis. Cornea 36:411-414. https://doi.org/10.1097/ICO.0000000000001103

9. Xia J, Tong J, Liu M et al (2020) Evaluation of coronavirus in tears and conjunctival secretions of patients with SARS-CoV-2 infection. J Med Virol 92:589-594. https://doi.org/10.1002/jmv. 25725

10. Colavita F, Lapa D, Carletti F et al (2020) SARS-CoV-2 Isolation From Ocular Secretions of a Patient With COVID-19 in Italy With Prolonged Viral RNA Detection. Ann Intern Med 173:242-243. https://doi.org/10.7326/M20-1176

11. Casagrande M, Fitzek A, Püschel K et al (2020) Detection of SARS-CoV-2 in Human Retinal Biopsies of Deceased COVID-19 Patients. Ocul Immunol Inflamm 28:721-725. https://doi.org/10. 1080/09273948.2020.1770301

12. Wu D, Koganti R, Lambe UP et al (2020) Vaccines and Therapies in Development for SARS-CoV-2 Infections. J Clin Med 9:1885. https://doi.org/10.3390/jcm9061885

13. Zhou L, Xu Z, Castiglione GM et al (2020) ACE2 and TMPRSS2 are expressed on the human ocular surface, suggesting susceptibility to SARS-CoV-2 infection. Ocul Surf 18:537-544. https://doi. org/10.1016/j.jtos.2020.06.007

14. Roehrich H, Yuan C, Hou JH (2020) Immunohistochemical Study of SARS-CoV-2 Viral Entry Factors in the Cornea and Ocular Surface. Cornea 39:1556-1562. https://doi.org/10.1097/ICO. 0000000000002509

15. Garza-Leon M (2016) Corneal endothelial cell analysis using two non-contact specular microscopes in healthy subjects. Int Ophthalmol 36:453-461. https://doi.org/10.1007/s10792-015-0133-Z 
16. Sheng H, Bullimore MA (2007) Factors affecting corneal endothelial morphology. Cornea 26:520-525. https://doi.org/10.1097/ ICO.0b013e318033a6da

17. Leem HS, Lee KJ, Shin KC (2011) Central corneal thickness and corneal endothelial cell changes caused by contact lens use in diabetic patients. Yonsei Med J 52:322-325. https://doi.org/10. 3349/ymj.2011.52.2.322

18. Seah I, Agrawal R (2020) Can the coronavirus disease 2019 (COVID-19) affect the eyes? A review of coronaviruses and ocular implications in humans and animals. Ocul Immunol Inflamm 28:391-395. https://doi.org/10.1080/09273948.2020.1738501

19. Chang L, Zhao L, Gong H et al (2020) Severe acute respiratory syndrome coronavirus 2 RNA detected in blood donations. Emerg Infect Dis 26:1631-1633. https://doi.org/10.3201/eid2607.200839

20. Lundberg B, Jonsson M, Behndig A (2005) Postoperative corneal swelling correlates strongly to corneal endothelial cell loss after phacoemulsification cataract surgery. Am J Ophthalmol 139:1035-1041. https://doi.org/10.1016/j.ajo.2004.12.080

21. O'Brien WJ, Palmer ML, Guy J, Taylor JL (1996) Endothelial barrier function and $\mathrm{Na}+\mathrm{K}+$-ATPase pump density in herpetic stromal disease. Investig Ophthalmol Vis Sci 37:29-36
22. Jin SX, Juthani VV (2020) Acute corneal endothelial graft rejection with coinciding COVID-19 infection. Cornea Publish Ah. https://doi.org/10.1097/ico.0000000000002556

23. Peng RM, Guo YX, Xiao GG, et al (2019) Characteristics of corneal endotheliitis among different viruses by in vivo confocal microscopy. Ocul Immunol Inflamm 1-9. https://doi.org/10.1080/ 09273948.2019.1678648

24. Sawant OB, Singh S, Wright RE, et al (2020) Prevalence of SARS-CoV-2 in human post-mortem ocular tissues. Ocul Surf. https://doi.org/10.1016/j.jtos.2020.11.002

Publisher's Note Springer Nature remains neutral with regard to jurisdictional claims in published maps and institutional affiliations.

This study was not presented at any conference. Authors have participated sufficiently in the work to take public responsibility for appropriate portions of the content. 